\title{
刍议土木工程施工管理中存在的问题及对策
}

胡延芳

宜都市国通投资开发有限责任公司，湖北 宜都 443300

[摘要]土木工程可以说是建筑领域中基础设施工程中较为重要的部分, 通常是一些道路工程, 水利工程等。在社会经济迅猛 发展的影响下，在最近的几年时间里，相关行政机构以及社会各界对于土木工程的质量越发的关注，并且在土木工程的建造 中投入了大量的人力物力。土木工程的建造水平与社会经济的发展和民众的生活都存在密切的关联, 但是就当前国内的土木 工程建造管理工作的现状来说，还存在这诸多的弊端，充分的联系实际情况，加大力度来增强土木工程施工管理工作，可以 更好的促进工程施工获得更加丰厚的收益，这篇文章围绕土木工程施工中现存的问题实施详细的研究，并针对定的对土木工 程施工管理工作的优化完善给予了一定的建议。

[关键词]土木工程；施工管理；问题；对策

DOI：10.33142/ec.v2i5.365 中图分类号：TU71 文献标识码：A

\section{Discussion on the Problems and Countermeasures in Civil Engineering Construction Management}

HU Yanfang

Yidu Guotong Investment Development Co., Ltd., Hubei Yidu, China 443300

\begin{abstract}
Civil engineering can be said to be an important part of infrastructure engineering in the field of construction, usually some road projects, water conservancy projects and so on. Under the influence of the rapid development of social economy, in recent years, the relevant administrative organizations and all sectors of society have paid more and more attention to the quality of civil engineering, and have invested a lot of manpower and material resources in the construction of civil engineering. The construction level of civil engineering is closely related to the development of social economy and the life of the people. However, as far as the current situation of civil engineering construction management in China is concerned, there are still many drawbacks, which are fully related to the actual situation. Increase In order to enhance the construction management of the civil engineering, the construction of the civil engineering can be better promoted, and the more abundant income can be obtained. This article will carry out the detailed research on the existing problems in the civil engineering construction. In addition, some suggestions are given to the optimization and improvement of the construction management of civil engineering.
\end{abstract}

Keywords: Civil engineering; Construction management; Problems; Countermeasures

引言

现如今在社会经济飞速进步的带动下, 使得建筑行业得到了显著的发展, 民众对于土木工程建造中的管理工作的 质量和效果越发的关注, 为了更好的对项目施工工作实施高效的管控, 确保施工工序按部就班的进行, 针对土木工程 施工管理工作中的弊端实施深入的研究分析，从中找到提升土木工程施工管理工作效率的方法。

\section{1 土木工程施工管理的特征}

\section{1 施工管理过程复杂繁琐}

当前，土木工程已被应用到道路、铁路等多个领域，因其所涉及范围的差异，使其施工管理过程也会有不同之处。 土木工程施工还会因外界因素的变化而受到影响, 并且, 各施工阶段都会应用与之相配套的管理办法 ${ }^{[1]}$ 。

\section{2 施工管理过程具有较高的流动性}

相关调查结果显示, 在施工过程中, 随着施工环境的改变, 施工人员也会产生变化, 约有 $73 \%$ 的施工人员仅在施工 期间在工地上作业, 且 $35 \%$ 的施工人员属于临时工, 未经受过正式的土木工程施工培训, 其具有较高的流动性, 因此, 要在施工周期中提高重视土木工程施工人员的流动特点, 重视对施工人员就操作合规性与安全警示进行专业培训 ${ }^{[2]}$ 。

\section{2 土木工程施工管理的意义}

土木工程施工管理并非是短时间内的一项工作，其充斥在工程建造的各个环节之中，对于工程施工质量的保证会 起到积极的影响作用。从工程前期的准备工作，施工技术的选择，施工物料设备的采买，施工人员的组织安排等等各 
项工作是是不能脱离施工管理工作的管控的, 进而这也充分的说明了土木工程施工管理工作在土木工程施工中的作用 是十分巨大的, 对于工程施工工作的稳定开展来说发挥出十分关键的基础作用。在经济快速发展趋势下, 使得大量的 城市基础土木工程项目的数量在不断的增加, 进而使得土木工程施工管理工作越发的受到了社会各界人士的关注, 并 且这项工作对于土木工程的未来发展情况也会起到一定的影响。现如今, 国内的土木工程施工管理工作还没有达到最 佳的状态, 诸如: 相关管理机制与现实需要不相符, 管理工作人员综合能力较差, 施工物料管理工作缺失等等, 严重 的阻碍了土木工程的健康稳定的发展, 使得土木工程的施工中频繁的发生危险事故, 使得大量的资源浪费, 进而结合 实际情况选择适当的方法来对施工管理工作的效率加以提升, 是现如今施工企业迫切需要解决的问题。

\section{3 土木工程施工管理中存在的问题}

\section{1 施工单位不重视}

在最近的几年时间里, 城市化进程正在大范围的推进, 各种类型的项目数量在不断的扩充, 这不但为土木工程行 业带来了发展机会, 并且也对土木工程行业提出了更高的要求。大部分的施工单位在实施土木工程施工建造工作的时 候, 一味的追求获得丰厚的利润, 不断地缩减成本花费, 对于施工管理工作的实施十分的忽视 ${ }^{[3]}$ 。使得施工现场的管理 工作没有条理性，管理工作无法实现既定的效果，进而对于工程施工周期以及工程施工质量的保证都是非常不利的。 在工程实际的建造中, 各个层级的人员对于安全施工思想十分的忽视, 大部分的安全消防设施都是表面文章, 进而一 旦出现危险事故其后果是非常严重的，甚至会导致大量的经济损失和人身伤亡。

\section{2 缺乏健全的监管机制}

因为施工企业对施工管理工作的忽视, 进而会导致项目施工中往往会出现违规操作的问题, 进而会使得工程施工 质量与施工管理工作无法实现既定的目标。在工程施工中没有落实管理工作, 会使得施工管理工作与实际需要存在不 相符的情况, 监管体制的不完善, 最终会导致管理部门重叠的情况, 很多的工程管理工作的实施因为在管理机制以及 方式上存在诸多的弊端, 进而导致施工现场施工秩序出现混乱, 施工物料没有放置在适合的位置, 工程建造使用的物 料质量不达标的问题层出不穷, 对于施工各项工作按部就班的进行是非常不利的, 进而会在工程建造中埋下诸多的危 险隐患。

\section{3 土木工程相关工作人员素质不高}

首先是施工人员的综合施工技术达不到既定的要求的标准, 严重的阻碍了工程施工工作的开展, 这样对于土木工 程施工质量的保证是非常不利的。其次, 是对土木工程实施管理工作的人员的工作态度以及责任心的缺失, 使得管理 工作无法全面的落实。

\section{4 施工技术控制不到位}

施工技术是工程建造质量以及效率保证的集成，并且在工程的建造中的作用是十分巨大的。通常来说，施工技术 其实质就是说在工程建造中所使用的各类有利于工程建造的专业技术。这些技术对工程整体结构质量以及施工周期的 保证都是会起到一定的影响的。其次, 良好的建筑设计方案与高水平的施工技术是分不开的, 施工技术是工程项目施 工建造的技术基础。现如今尽管科学技术水平取得了较为显著的进步, 使得国内的土木工程施工技术随之取得了明显 的发展, 但是在实际的工程建造中还是存在诸多的不稳定的因素, 这就需要我们对施工技术的管控工作需要提升力度。

\section{4 土木工程施工管理问题的对策分析}

\section{1 制定和完善管理制度}

在实施土木工程施工管理工作管控机制的编制之前, 最为重要的是需要安排专业的设计人员对工程实施整体规划, 对施工管理工作的实施制定切实可行的预算, 其次, 需要确保工程管理工作的实施具有良好的高效性, 并且各项工作 需要进行细致的划分, 对工程管理机制的制定需要切实的联系实际情况, 并且在后期的实施中确保一定的效率和质量, 全面的推动管理工作的开展。在工程管理工作的实施中, 一旦发下管理机制中的问题, 需要第一时间进行纠正, 并联 系实际情况加以优化完善。

\section{2 重视员工安全意识的培养}

功臣的建造企业需要加大力度来定期组织各个层级的人员进行安全生产方面的知识培训和学习, 从根本上提升人 们的安全生产的思想意识, 有效的规避施工中的危险事故的发生, 这样对于施工人员的人身安全也会有所保证。工程 的管理机制在确保施工周期的基础上，也需要组织施工人员对管理机制进行学习，充分的了解管理机制的实际意义， 并且编制出完善的施工安全责任制度。其次还需要加大力度来推行安全施工思想的宣传工作, 促使各个层级的人员都 
能够充分的认识到安全生产的重要性。

\section{3 重视设备材料管理}

土木工程在建筑行业中作用是十分巨大的, 想要确保土木工程的施工质量, 最为重要的是从施工物料以及施工机 械的采买入手。在最近的几年时间里, 土木工程项目的数量在不断的增加, 进而对施工物料的数量也在不断的扩充, 为了保证工程结构质量, 务必要针对施工物料的质量以及施工机械的性能实施切实的监督管控, 杜绝质量不合格的施 工物料运用到工程建造之中。其次, 在工程实际建造中, 需要高效的利用前沿施工机械, 这样能够有效地减少施工过 程中的能源消耗量, 促使项目成本明显的减少, 并且提升工程建造的效率, 促使施工企业获得更加丰厚的收益。再有, 我们还需要对施工物料的存储加以切实的管控, 结合各类物料的性质, 选择适当的存储地, 并且严格的遵照规范标准 来对施工物料加以存放, 这样才能从根本上提升工程的时候质量, 并且推动施工工作按部就班的进行。创建物料进场 管理体系, 对所有的进入到施工现场的施工物料的质量需要进行检核, 在检查中采用抽样检查的形式, 一旦发现施工 物料存在质量问题，需要第一时间上报，并联系物料供应厂家进行调换 ${ }^{[5]}$ 。

\section{4 控制工程施工进程}

施工进程管理贯穿整个项目当中，分为施工前、施工过程中、施工后三个方面进行管理，确保工程按预期进行实 施, 在确保工期的同时对工程质量进行控制, 对施工现场的安全进行全面管理。土木工程的施工现场, 管理人员发现 施工过程中存在的问题应及时进行纠正，保证施工进展。在土木工程的施工过程中，应对分包企业资质进行严格评估， 健全招投标管理制度, 消除地方性保护色彩的影响, 避免出现恶意拉低工程造价的现象。基于健全的土木工程项目招 投标管理制度, 不仅能够有效保证招投标工作的质量, 还可以提高项目施工质量, 提高承包企业经济利益。在进行土 木工程施工时, 若发现问题, 应立即采取相应应对措施进行解决, 这将对工程质量大有帮助, 并能促进工程项目的建 设及其顺利进行。施工进程管理和工程成本有直接的关系, 因此, 控制好施工进程才能有效控制成本, 在保证工程质 量的同时，确保施工企业的利润。

\section{5 加强土木工程施工后的质量控制}

在工程建造完成之后，需要有专业的工作人员对工程质量进行验收，确保工程质量达到既定的效果。

\section{结语}

在社会经济快速发展的带动下, 推动了城镇化建设的大范围的铺展开来, 这样就为土木工程建造创造了发展的机 遇, 有利的推动了国内土木工程施工管理工作的健康发展, 这对于促进我国社会的和谐发展也起到了积极的影响作用。

\section{[参考文献]}

[1]陈涛.浅析现代化土木工程施工管理中的问题与对策 [J].绿色环保建材, 2018(07): 197-198.

[2]裴藏蓕.浅谈土木工程施工管理问题及对策 [J]。四川建材, 2017,43(08) : 177-178.

[3] 唐伟鹏.土木工程施工管理中的常见问题及对策分析 [J].建材技术与应用,2016(03) : 43-44.

[4] 张炎赠. 土木工程施工管理中存在的主要问题分析 [J]. 四川建材,2016,42(01): 261-263.

[5]吴潇杭,钱杭伟.土木工程施工管理中存在的问题分析 [J].中华民居 (下旬刊) , 2013 (07) : 222-223.

作者简介: 胡延芳 (1981-), 毕业学校: 武汉理工大学; 现就职于宜都市国通投资开发有限责任公司青林古镇开发有 限责任公司常务副总经理。 